\title{
First Clinical Impressions on the Integrated Corneal Tomography and Corneal Deformation with Scheimpflug Imaging
}

\author{
1 Jorge S Haddad, ${ }^{2}$ Eliza Barnwell, ${ }^{3}$ Karolinne M Rocha, ${ }^{4}$ George O Waring IV, ${ }^{5}$ Renato Ambrosio Jr
}

\begin{abstract}
The purpose of this study is to report the preliminary findings and the retrospective clinical impressions of the integrated corneal tomography and corneal deformation parameters with a dynamic ultra-high-speed Scheimpflug camera equipped with a noncontact tonometer. Twelve eyes of six patients were evaluated by the Scheimpflug imaging system of the Pentacam HR and Corvis ST (OCULUS Optikgeräte $\mathrm{GmbH}$, Wetzlar, Germany) devices. The parameters used were the Belin/Ambrósio deviation (BAD-D) and Corvis biomechanical index ( $\mathrm{CBI})$, as well as the recently published tomographic and biomechanical index (TBI), combined with a detailed clinical data and evaluation of normal eyes and patients with different stages of corneal ectasia.
\end{abstract}

Keywords: Case series, Corneal diseases, Corneal topography, Ectasia/diagnosis, Keratoconus, Tomography.

How to cite this article: Haddad JS, Barnwell E, Rocha KM, Waring IV GO, Ambrosio Jr R. First Clinical Impressions on the Integrated Corneal Tomography and Corneal Deformation with Scheimpflug Imaging. Int J Kerat Ect Cor Dis 2017;6(2):101-109.

Source of support: Nil

Conflict of interest: None

\section{INTRODUCTION}

Corneal topography refers to the anterior measurement of the cornea and has been useful for the past few decades in the detection of several pathologies, such as keratoconus and corneal astigmatism. ${ }^{1}$ However, the first alteration in mild and subclinical forms of corneal ectasia is the subtle elevation of the posterior corneal curvature,

\footnotetext{
${ }^{1}$ Postdoctoral Fellow, ${ }^{2}$ Intern, ${ }^{3}$ Refractive and Corneal Head ${ }^{4,5}$ Clinical Director

${ }^{1-3}$ Department of Ophthalmology, Storm Eye Institute, Medical University of South Carolina, Mount Pleasant, South Carolina USA

${ }^{4}$ Department of Ophthalmology, Waring Vision Institute, Mount Pleasant, South Carolina, USA

${ }^{5}$ Department of Ophthalmology, Instituto de Olhos Renato Ambrosio, Rio de Janeiro, Brazil

Corresponding Author: Jorge S Haddad, 167 Ashley Ave Charleston, South Carolina, USA, Phone: +8433277934, e-mail: jshaddad2@hotmail.com
}

which is difficult to identify through conventional topographic exams. $^{2}$

Corneal ectasia is classified based on the thinning and protrusion of corneal structures. Its progression to more advanced disease is multifactorial and depends on both intrinsic factors, such as corneal biomechanics and genetic predisposition, and extrinsic factors, such as eye rubbing and associated atopy, as well as the amount of tissue altered during surgical procedures in predisposed individuals. ${ }^{3,4}$ With increased demand for refractive surgery and the use of femtosecond lasers, it is important to consider that the residual postoperative stroma may decompensate in a predisposed cornea.

There are currently two devices available on the market for performing corneal biomechanics measurements in vivo: The ocular response analyzer (Reichert Ophthalmic Instruments, Depew, New York, USA), which is a dynamic bidirectional applanation device, ${ }^{5,6}$ and the Corvis ST (Oculos Optikgeräte GmbH, Wetzlar, Germany), which is a noncontact tonometer with an air pulse that uses an ultra-high-speed Scheimpflug camera to monitor corneal deformation. ${ }^{7,8}$ Despite its potential, the former has demonstrated limited ability for screening of ectatic disease. ${ }^{9,10}$ The latter features advanced parameters that can help detect early ectasia and fruste keratoconus with higher accuracy. ${ }^{11}$ In addition to the $\mathrm{CBI},{ }^{12}$ which has been shown in the literature as an excellent predictor of early ectasias, the $\mathrm{BAD}^{13}$ and TBI parameters based on Scheimpflug corneal tomography and corneal deformation parameters greatly contribute to the understanding of corneal ectasia. ${ }^{11}$

The purpose of this study is to report a series of cases using the Corvis ST device along with tomographic and clinical parameters to determine the risk of developing corneal ectasia in patients with subtle predisposing topographic changes.

\section{CASE REPORTS}

\section{Case 1}

A 38-year-old male diagnosed with keratoconus in the left eye 15 years earlier presented for follow-up complaining of progressive vision loss in the left eye. The patient's uncorrected visual acuity (UCVA) was Counting Fingers (CF) 6 FT in the right eye (OD) and CF 3 FT in the left eye 


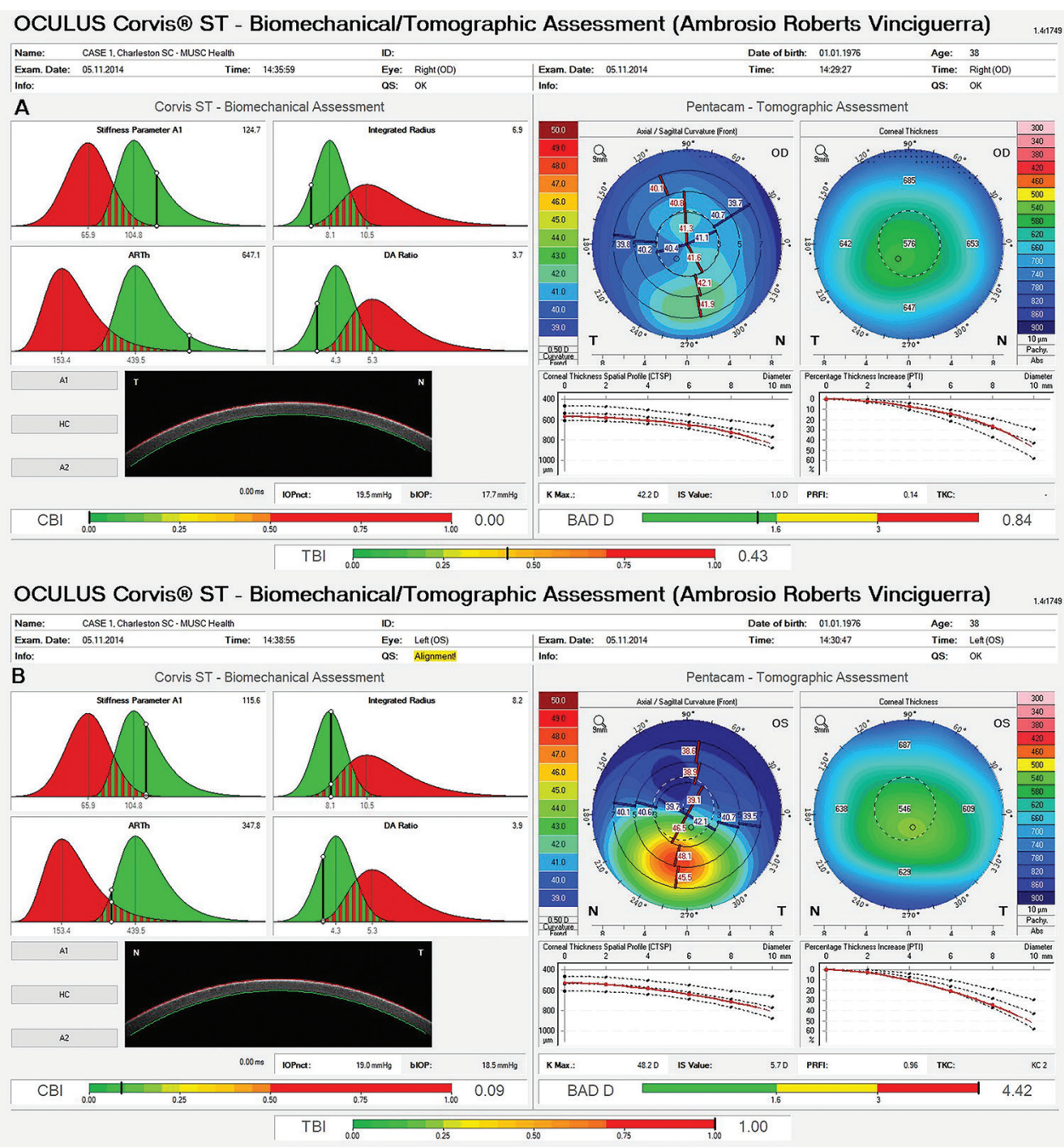

Figs $1 \mathrm{~A}$ and $\mathrm{B}$ : Corvis ${ }^{\circledR} \mathrm{ST}$ : Biomechanical/tomographic assessment. (A) There is a mild inferior steepening in the right eye with a borderline TBI. (B) Left eye was diagnosed with stage 2 keratoconus, inferior stepenning with the TBI over the cut-off limit is observed

(OS). His best-corrected visual acuity (BCVA) was 20/20 OD (sph -6.75 , cyl +0.75 at 106) and 20/25 OS (sph -6.25 , cyl +1.75 at 177).

The central corneal thickness was $576 \mu \mathrm{m}$ OD and $546 \mu \mathrm{m}$ OS. Anterior corneal curvature measured using Pentacam ${ }^{\circledR}$ HR revealed a very mild inferior steepening OD with Kmax 42.2D and inferior-superior asymmetry of 1.0D. A topometric pattern of keratoconus stage 2 was identified in the left eye with $\mathrm{Kmax} 48.2 \mathrm{D}$ and inferiorsuperior asymmetry of 5.7D.

The deviation value from BAD-D (version 3) was 0.84 $\mathrm{OD}$, which was below the cut-off value for forme fruste keratoconus. The patient was diagnosed with keratoconus stage 2 OS based on the corneal topography classification proposed by Amsler according to a Kmax of 48.2D, with BAD-D of 4.42 on corneal tomography; CBI was $0 \mathrm{OD}$ and 0.09 OS; TBI values were 0.43 OD and 1.00 OS (Fig. 1). This was consistent with the diagnosis of forme fruste keratoconus OD and mild keratoconus OS, not unilateral ectatic disease OS.

\section{Case 2}

A 17-year-old male presented for keratoconus evaluation. The patient's UCVA was 20/40 OD and 20/60 OS. His BCVA was 20/20 OD (sph -1.75 , cyl -0.75 at 174) and 20/20 OS (sph -1.75 , cyl -0.50 at 165).

The front sagittal curvature measured using Penta$\mathrm{cam}^{\circledR} \mathrm{HR}$ demonstrated with-the-rule astigmatism with Kmax of 47.6D OD and 46.7D OS. Tomographic evaluation demonstrated central steepening in both eyes. Pachymetric progression indices were normal; BAD-D was $1.81 \mathrm{OD}$ and $1.42 \mathrm{OS}$, over the cut-off value of normality. The CBI was $0.05 \mathrm{OD}$ and $0 \mathrm{OS}$, and TBI values were $0.12 \mathrm{OD}$ and 0.31 OS (Fig. 2). These values were consistent with the diagnosis of mild (fruste) ectasia, which we consider to be as high susceptibility for progression.

\section{Case 3}

A 28-year-old female scheduled an appointment to enquire about refractive surgery. The patient was a 


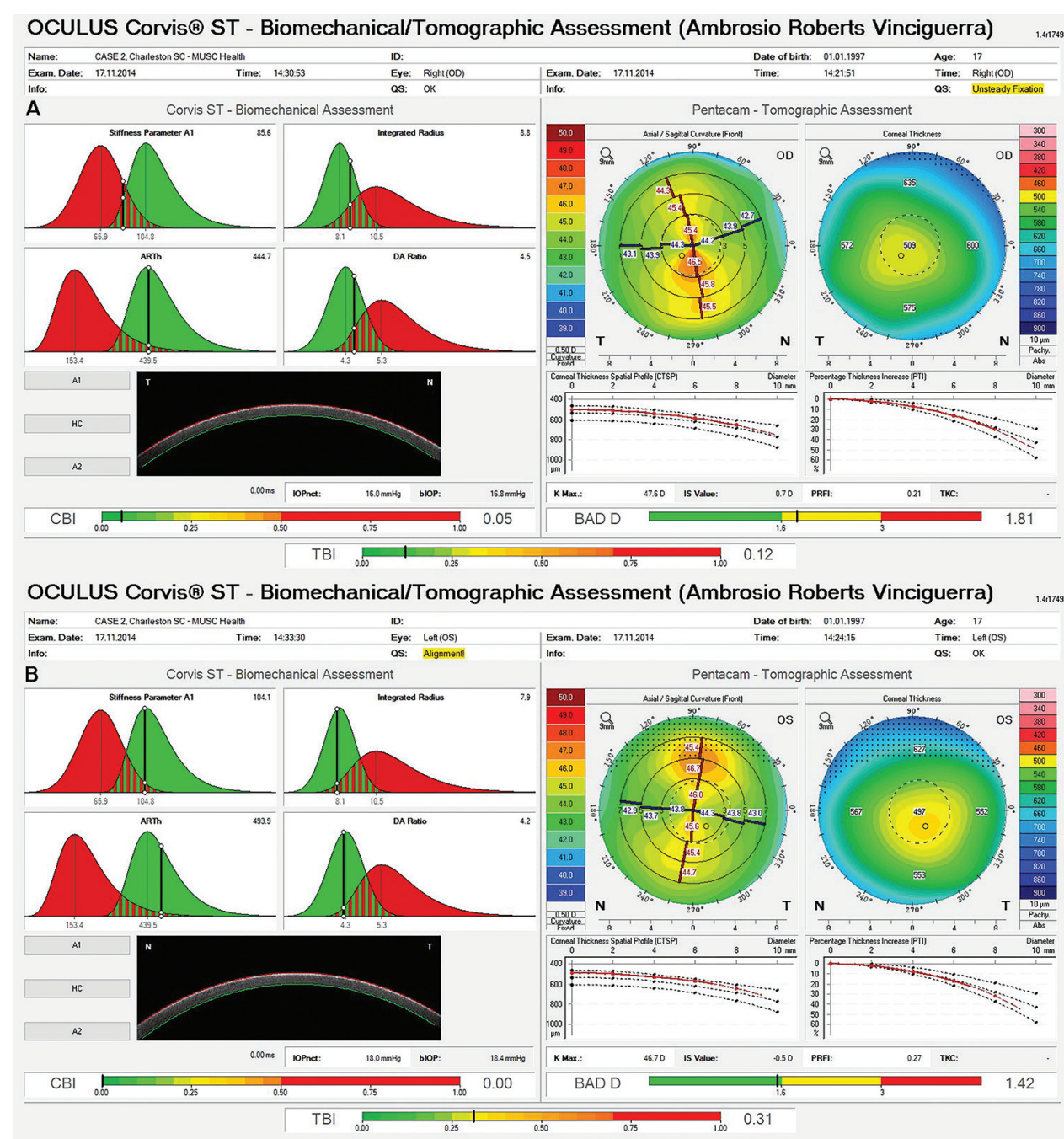

Figs 2A and B: Corvis ${ }^{\circledR}$ ST: Biomechanical/tomographic assessment. (A) Note the central steepening in the right eye with the TBI under the cutt-off limit. (B) Left eye: Same pattern is observed with a normal TBI

contact lens wearer but has not worn contacts for 4 days prior to the appointment. She had no prior history of any major eye diseases or surgeries. The patient's UCVA was CF at 6 FT in both eyes. Her BCVA was 20/20 OD (sph -4.25 , cyl -0.50 at 100) and 20/20 OS (sph -5.25 , cyl -0.50 at 17). The central corneal thickness was $596 \mu \mathrm{m}$ OD and $590 \mu \mathrm{m}$ OS.

The front sagittal curvature measured using Pentacam ${ }^{\circledR}$ HR demonstrated a with-the-rule astigmatism with Kmax of 48.9D OD and 48.8D OS. Tomographic evaluation demonstrated normal anterior and posterior curvature. Pachymetric progression indices were normal. The BAD-D was $2.15 \mathrm{OD}$ and $2.34 \mathrm{OS}$, under the cut-off value of normality; CBI was $0.65 \mathrm{OD}$ and $0.97 \mathrm{OS}$, and TBI values were $0.70 \mathrm{OD}$ and $0.58 \mathrm{OS}$ (Fig. 3).

\section{Case 4}

A 33-year-old male scheduled an appointment to enquire about refractive surgery. He was a contact lens wearer but had not worn contacts for 4 days prior to the appointment.
His only significant ocular history was a corneal abrasion in 1991 in the right eye due to an injury with a stick. The patient's UCVA was 20/400 OD and 20/200 OS. His BCVA was 20/20 OD (sph -4.25 , cyl -1.25 at 4 ) and 20/20 OS (sph -4.00 , cyl -0.50 at 140 ). The central corneal thickness was $549 \mu \mathrm{m}$ OD and $548 \mu \mathrm{m}$ OS.

The patient was found to have a normal topographic pattern in both eyes. The front sagittal curvature measured using Pentacam ${ }^{\circledR}$ HR demonstrated with-the-rule astigmatism with Kmax of 47.2D OD and 47.5D OS. Tomographic evaluation demonstrated normal anterior and posterior curvature. Pachymetric progression indices were normal. The BAD-D was 1.09 OD and 1.38 OS, over the cut-off value of normality; CBI was 0 in both eyes, and TBI values were 0.01 OD and 0.00 OS (Fig. 4), which are within normal values.

\section{Case 5}

A 36-year-old female scheduled an appointment to enquire about refractive surgery. She had no history of 


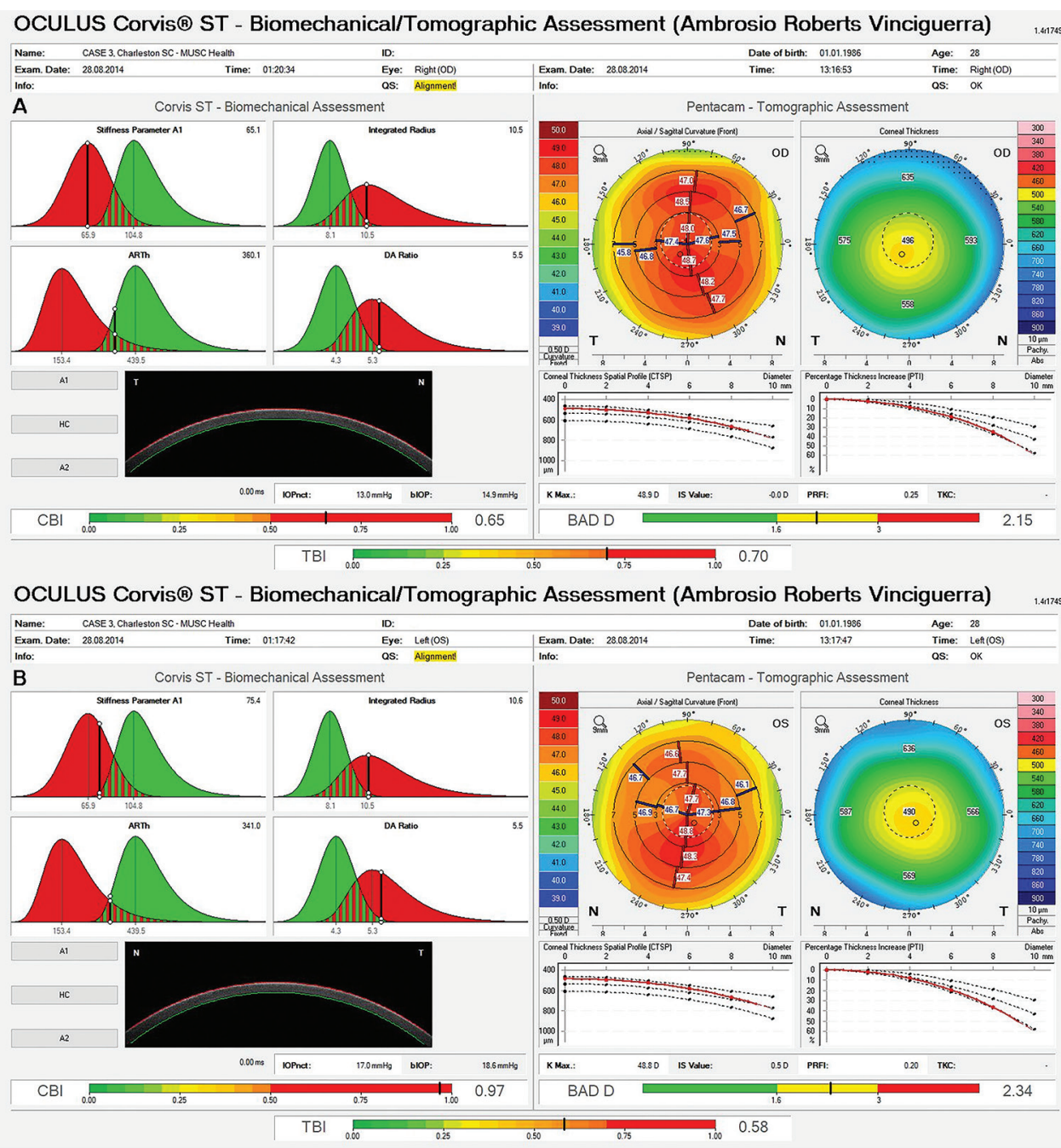

Figs 3A and B: Corvis ${ }^{\circledR} \mathrm{ST}$ : Biomechanical/tomographic assessment. (A) Note the central steepening in the right eye with the TBI over the cut-off limit. (B) Left eye: Similar pattern is observed with the TBI over the cut-off limit

significant eye diseases or surgery. The patient's UCVA was $20 / 30 \mathrm{OD}$ and $20 / 20 \mathrm{OS}$. Her BCVA was 20/20 OD (sph -0.75 , cyl -0.50 at 95 ) and 20/20 OS (sph -0.25 , cyl -0.50 at 50). The central corneal thickness was $581 \mu \mathrm{m}$ OD and $572 \mu \mathrm{m}$ OS.

The front sagittal curvature measured using Pentacam ${ }^{\circledR}$ HR demonstrated irregular astigmatism with Kmax of 45.9D OD and 45.2D OS. Tomographic evaluation demonstrated nasal steepening in both eyes. Pachymetric progression indices were normal; BAD-D was $0.54 \mathrm{OD}$ and $0.36 \mathrm{OS}$, under the cut-off value of normality; CBI was 0 in both eyes, and TBI values were 0.00 in both eyes as well (Fig. 5).

\section{Case 6}

A 21-year-old male who uses soft contact lenses scheduled an appointment to enquire about refractive surgery. He had not worn contact lenses for 2 weeks prior to the appointment. He had no history of significant eye disease other than an infection during childhood. The patient's UCVA was 20/100 OD and 20/200 OS. His BCVA was $20 / 15$ OD (sph -1.25 , cyl -1.75 at 7 ) and 20/15 OS (sph -2.50, cyl -1.00 at 170). The central corneal thickness was $561 \mu \mathrm{m}$ OD and $565 \mu \mathrm{m}$ OS.

The patient presented with a normal topographic pattern in both eyes. The front sagittal curvature measured using Pentacam ${ }^{\circledR}$ HR demonstrated with-the-rule astigmatism with Kmax of 44.5D OD and 44.2D OS. Tomographic evaluation demonstrated normal anterior and posterior curvatures. Pachymetric progression indices were normal. The CBI was 0 in both eyes; BAD-D was $1.00 \mathrm{OD}$ and $1.16 \mathrm{OS}$, acceptable in the cut-off value of normality. The CBI and TBI values were 0.00 in both eyes (Fig. 6).

\section{DISCUSSION}

Advanced diagnostic interpretations using corneal topography, three-dimensional corneal tomography, 


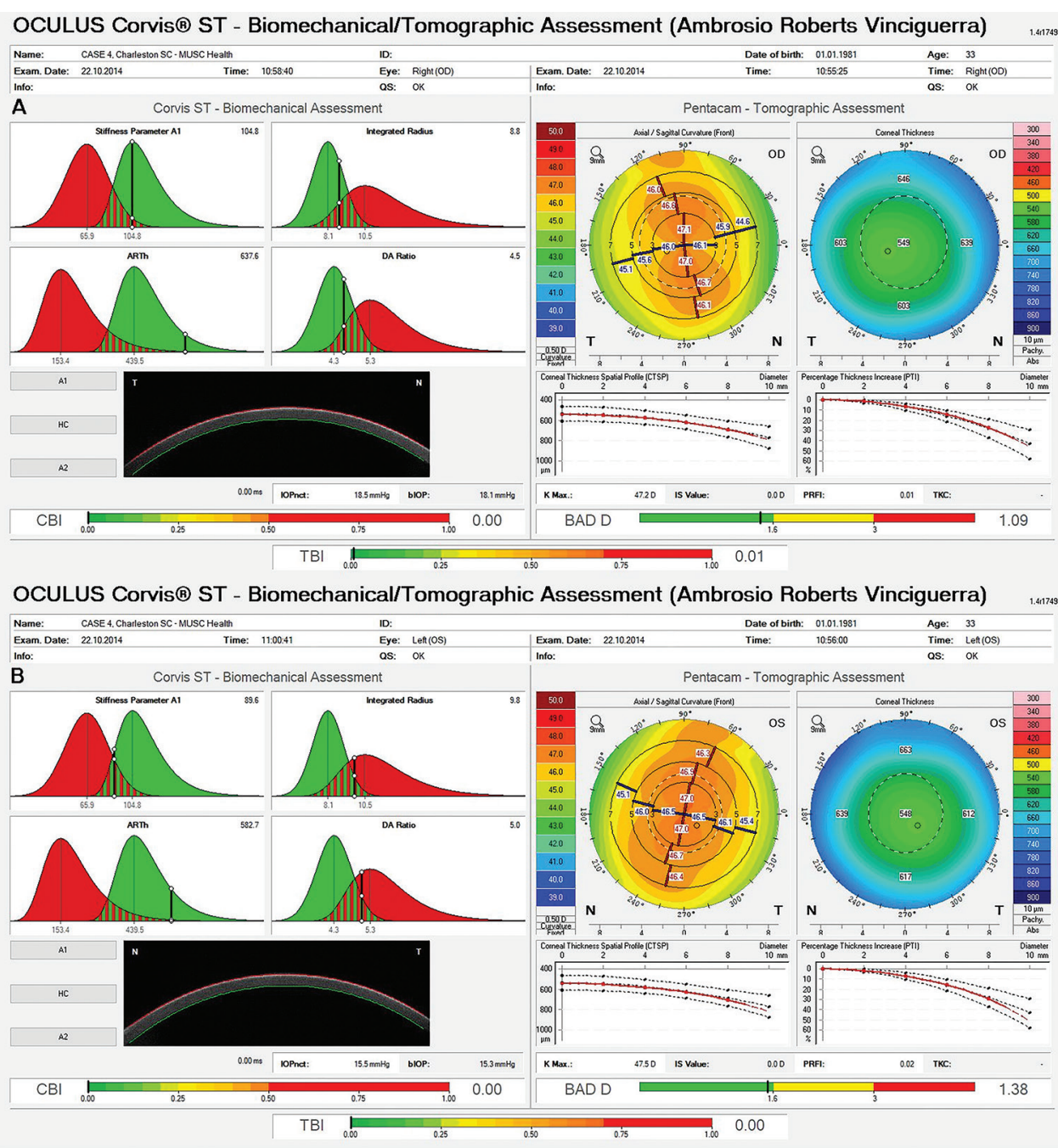

Figs 4A and B: Corvis ${ }^{\circledR}$ ST: Biomechanical/tomographic assessment. (A) With-the-rule astigmatism in the right eye with a normal TBI. (B) Left eye shows the same pattern with a normal TBI

and biomechanical evaluation are useful tools in the diagnosis of subtle cornea pathologies in patients who are asymptomatic. ${ }^{14}$

Candidates for refractive surgery often have no to mild topographic changes that may progress to corneal ectasia after laser refractive surgery. ${ }^{15}$ Scheimpflug corneal tomography is effective in detecting moderate to severe changes of the anterior corneal surface but has lower sensitivity in mild ectasia or fruste keratoconus. ${ }^{16}$ It is worth mentioning that genetic factors contribute to alterations in the posterior cornea in most cases of keratoconus, and screening is done chiefly in young patients with a family history. ${ }^{17,18}$

In our case series, we were able to detect patients with normal topographic changes but altered Corvis corneal deformation parameters, which helped us differentiate normal cornea from suspicious keratectasia. We considered normal topography patients with a normal curvature in frontal cornea mapping, a keratoconus percentage index (KISA\%) score lower than 60 , and a paracentral inferior-superior value at $6 \mathrm{~mm}$ less than $1.45 .{ }^{19}$ Tables 1 and 2 display the summary of the main parameters for analysis of the cases. In Case 1, we noticed a typical occurrence of unilateral ectasia in one eye with subtopographic alteration in the fellow eye. All parameters were normal in the subclinical eye except for the TBI, which was above the cut-off value. It is important to clarify that the TBI artificial intelligence algorithm is not simply the integration of the BAD-D and the CBI. It computes raw data from the tomographic and biomechanical analysis from Scheimpflug images derived from Pentacam and Corvis ST using the random forest approach. ${ }^{11}$

Case 2 demonstrates a bilateral fruste keratoconus presentation with absence of topometric advancement. The patient was advised to return for regular follow-up exams and monitoring. Of note, initial cases of unilateral keratoconus are rare but deserve special attention, as the fellow eye is often masked as a fruste forme or is undetected with conventional topographic examinations. ${ }^{10,20}$

In Case 3, we noticed altered topography and Corvis parameters, and the patient was advised to not proceed 


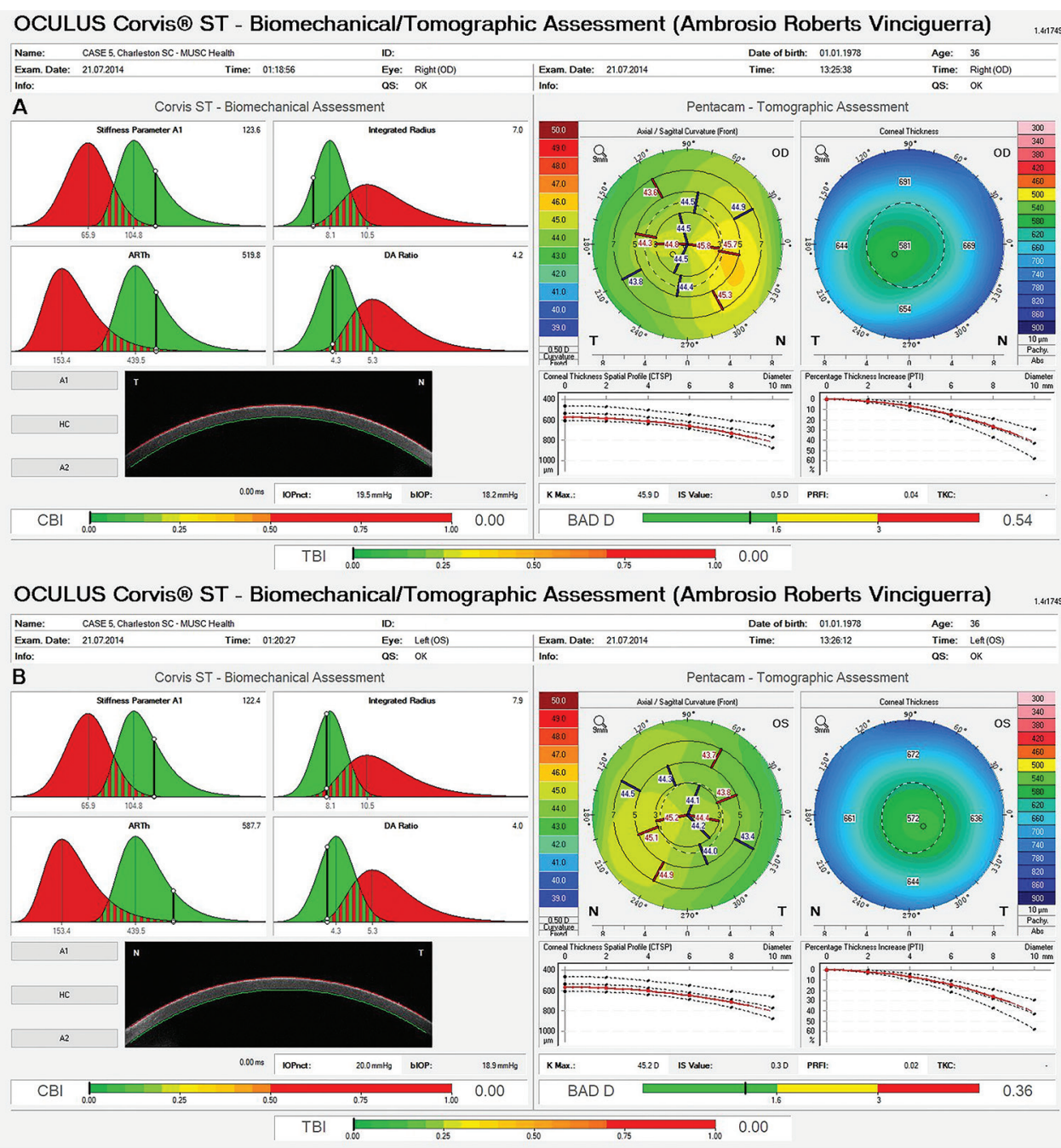

Figs 5A and B: Corvis ${ }^{\circledR}$ ST: Biomechanical/tomographic assessment. (A) Note a mild nasal steepening in the right eye with a normal TBI. (B) Left eye: Similat topogographic pattern with a normal TBI

with refractive surgery. In Cases 4, 5, and 6, mild topographic changes were seen; however, indices were normal. The data are illustrated in Table 1.

In a parallel study, Vinciguerra et $\mathrm{al}^{12}$ showed that CBI had a $97.5 \%$ accuracy for detecting clinical ectasias. A recent retrospective study by Ambrosio et al ${ }^{11,13}$ showed high sensitivity in detecting subclinical ectasias with normal topography when $\mathrm{BAD}$, which provides a comprehensive screening, is combined with the newly developed TBI parameter.

The Corvis device's advanced parameters combined with clinical and tomographic changes increase the sensitivity and specificity of cases that would otherwise go unnoticed and could progress to corneal decompensation if subjected to surgery.

\section{CONCLUSION}

The interpretation of the biomechanical parameters of the cornea is challenging due to the behavior of the cornea's viscoelastic properties and by the relatively limited available data. ${ }^{21}$ Novel advanced parameters have been proven useful for improving the detection of subclinical ectasia cases and for providing additional information to guide clinical decision.

We were able to distinguish suspicious cases that would be considered normal by isolated front surface corneal topography from cases with an asymmetric pattern that would not likely have ectasia. Retrospective analysis of the advanced parameters of patients with relatively dubious clinical conditions demonstrated usefulness for clinical decision making mainly regarding the TBI. By combining data from corneal tomography of Pentacam ${ }^{\circledR}$ HR with the new parameters of Corvis ST, one could make a detailed and careful analysis to detect early patients who could develop corneal ectasias and who could otherwise go unnoticed.

Future prospective and retrospective studies should be done to further validate the integration of corneal biomechanics with Scheimpflug images, so that the ability of the TBI for characterizing ectatic corneal disease and 


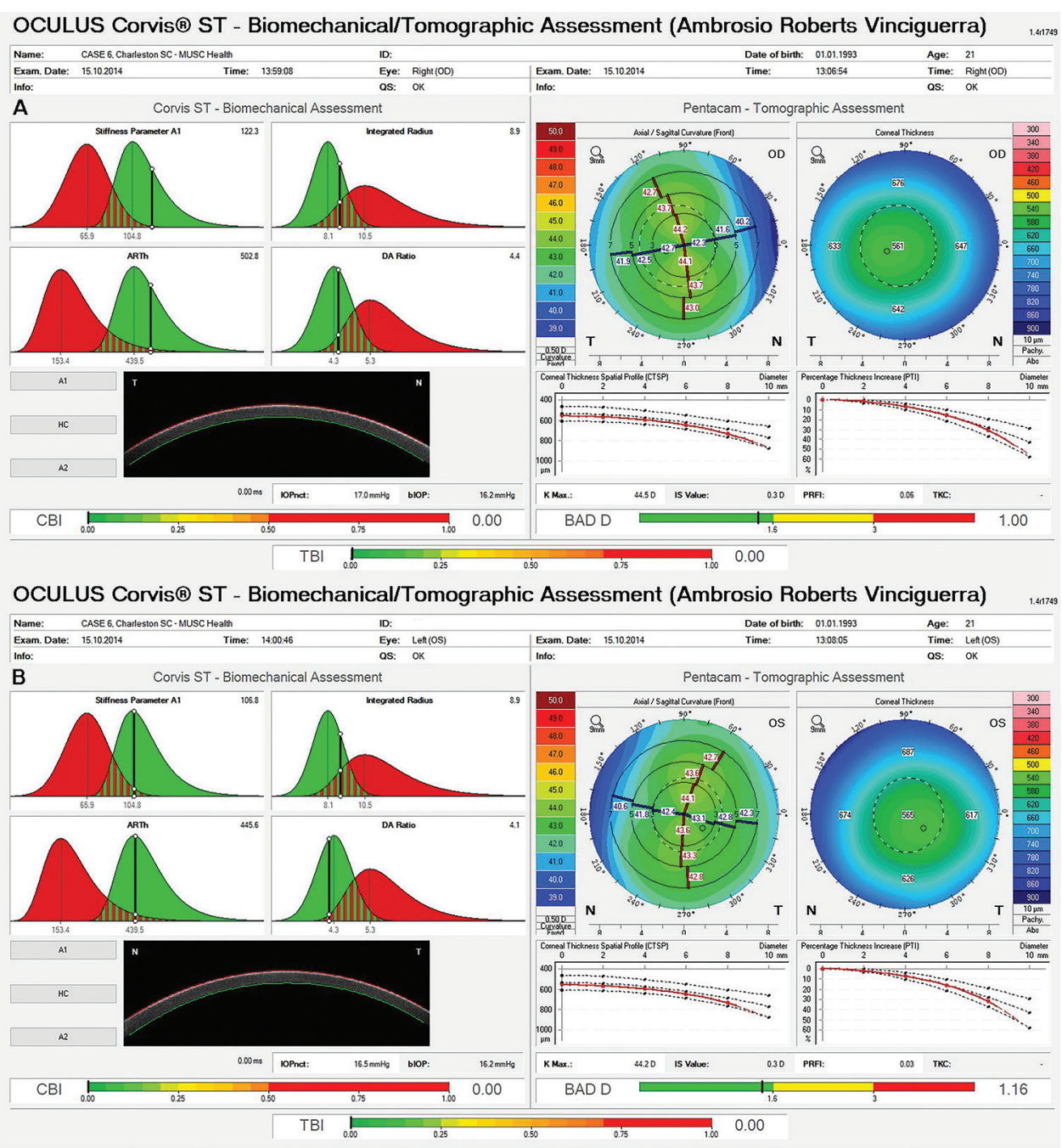

Figs 6 A and B: Corvis ${ }^{\circledR} \mathrm{ST}$ : Biomechanical/tomographic assessment. (A) With-the-rule astigmatism in the right eye with a normal TBI. (B) Left eye shows the same pattern with a normal TBI

Table 1: Ectasia cases

\begin{tabular}{|c|c|c|c|c|c|c|c|c|c|}
\hline \multirow[b]{2}{*}{ Parameter } & \multicolumn{2}{|c|}{ Case 1} & \multicolumn{2}{|c|}{ Case 2} & \multicolumn{2}{|c|}{ Case 3} & \multirow[b]{2}{*}{ Cutoff } & \multirow[b]{2}{*}{ Sens } & \multirow[b]{2}{*}{ Spec } \\
\hline & Right & Left & ight & Left & Right & Left & & & \\
\hline KKS & - & KC 2 & - & - & & & - & - & - \\
\hline IHD & 0.015 & 0.100 & 0.008 & 0.025 & 0.011 & 0.010 & $>0.015$ & 97.11 & 98.87 \\
\hline Kmax (front) & 42.2 & 48.2 & 47.6 & 46.7 & 48.9 & 48.8 & $>47.17$ & 91.56 & 89.1 \\
\hline KISA & 2.31 & 269.31 & 4.702 & 0.922 & 2.353 & 5.765 & $>63.7$ & 88.22 & 98.12 \\
\hline SRAX & 6.75 & 91.84 & 7.62 & 1.49 & 7.06 & 15.12 & $>14.75$ & 82.22 & 48.5 \\
\hline I-S value & 1.0 & 5.8 & 0.7 & -0.5 & 0 & 0.5 & $>1.21$ & 96.22 & 95.86 \\
\hline Central-K & 41.103 & 41.536 & 45.482 & 45.062 & 48.024 & 47.736 & $>45.1$ & 76.44 & 80.08 \\
\hline $\begin{array}{l}\text { Anterior elevation at thinnest point using } \\
\text { BFS } 8.0\end{array}$ & 3 & 11 & 4 & 0 & 2 & 3 & $>5$ & 91.5 & 99.0 \\
\hline $\begin{array}{l}\text { Posterior elevation at thinnest point } \\
\text { using BFS } 8.0\end{array}$ & 7 & 29 & 7 & 1 & 5 & 5 & $>14$ & 96.22 & 98.87 \\
\hline ART max & 421 & 240 & 424 & 365 & 367 & 322 & $\leq 344$ & 95.78 & 98.5 \\
\hline ART avg & 598 & 385 & 512 & 458 & 413 & 413 & $\leq 473$ & 96.89 & 97.37 \\
\hline Thinnest value & 570 & 530 & 505 & 490 & 492 & 488 & $\leq 514$ & 89.33 & 90.98 \\
\hline PRFI & 0.14 & 0.96 & 0.21 & 0.27 & 0.25 & 0.20 & $>0.15$ & 94.3 & 99.8 \\
\hline BAD (v3) & 0.84 & 4.42 & 1.81 & 1.42 & 2.15 & 2.34 & $>2.32$ & 98.22 & 100 \\
\hline TBI & 0.43 & 1.00 & 0.12 & 0.31 & 0.70 & 0.58 & $>0.30$ & 96.2 & 98.7 \\
\hline
\end{tabular}

Sens: Sensitivity; Spec: Specificity; KKS: Keratoconus stage; IHD: Index of height decentration; Kmax (front): Maximum axial curvature of the front surface; SRAX: Relative skewing of the steepest radial axes; I-S value: Inferior-superior asymmetry in keratometry; BFS 8.0 $\mathrm{mm}$ : Best fit sphere to $8.0 \mathrm{~mm}$ zone; ART: Ambrosio relational thickness calculated for the average and maximum progression indices (ART avg and ART max); PRFI: Pentacam random forest index; BAD (v3): Belin/Ambrosio deviation index (third generation [version 3]); 
Table 2: Nonectasia cases

\begin{tabular}{|c|c|c|c|c|c|c|c|c|c|}
\hline \multirow[b]{2}{*}{ Parameter } & \multicolumn{2}{|c|}{ Case 1} & \multicolumn{2}{|c|}{ Case 2} & \multicolumn{2}{|c|}{ Case 3} & \multirow[b]{2}{*}{ Cutoff } & \multirow[b]{2}{*}{ Sens } & \multirow[b]{2}{*}{ Spec } \\
\hline & Right & Left & Right & Left & Right & Left & & & \\
\hline KKS & - & - & - & - & - & - & - & - & - \\
\hline $\mathrm{IHD}$ & 0.005 & 0.003 & 0.021 & 0.017 & 0.012 & 0.013 & $>0.015$ & 97.11 & 98.87 \\
\hline Kmax (front) & 47.2 & 47.5 & 45.9 & 45.2 & 44.5 & 44.2 & $>47.17$ & 91.56 & 89.1 \\
\hline KISA & 1.29 & 6.737 & 42.277 & 45.273 & 2.267 & 4.504 & $>63.7$ & 88.22 & 98.12 \\
\hline SRAX & 3.87 & 20.21 & 141.83 & 135.82 & 4.01 & 11.78 & $>14.75$ & 82.22 & 48.5 \\
\hline I-S value & 0 & 0 & 0.5 & 0.3 & 0.3 & 0.3 & $>1.21$ & 96.22 & 95.86 \\
\hline Central-K & 46.639 & 46.933 & 44.936 & 44.591 & 43.461 & 43.387 & $>45.1$ & 76.44 & 80.08 \\
\hline $\begin{array}{l}\text { Anterior elevation at thinnest point } \\
\text { using BFS } 8.0\end{array}$ & 2 & 2 & -1 & -1 & 5 & 4 & $>5$ & 91.5 & 99.0 \\
\hline $\begin{array}{l}\text { Posterior elevation at thinnest point } \\
\text { using BFS } 8.0\end{array}$ & 7 & 7 & 6 & 5 & 5 & 5 & $>14$ & 96.22 & 98.87 \\
\hline ART max & 467 & 423 & 526 & 500 & 458 & 384 & $\leq 344$ & 95.78 & 98.5 \\
\hline ART avg & 602 & 541 & 615 & 635 & 553 & 538 & $\leq 473$ & 96.89 & 97.37 \\
\hline Thinnest value & 544 & 543 & 577 & 569 & 559 & 557 & $\leq 514$ & 89.33 & 90.98 \\
\hline PRFI & 0.01 & 0.02 & 0.04 & 0.02 & 0.06 & 0.03 & $>0.15$ & 94.3 & 99.8 \\
\hline BAD (v3) & 1.09 & 1.38 & 0.54 & 0.36 & 1.0 & 1.16 & $>2.32$ & 98.22 & 100 \\
\hline TBI & 0.01 & 0 & 0 & 0 & 0 & 0 & $>0.30$ & 96.2 & 98.7 \\
\hline
\end{tabular}

Sens: Sensitivity; Spec: Specificity; KKS: Keratoconus stage; IHD: Index of height decentration; Kmax (front): Maximum axial curvature of the front surface; SRAX: Relative skewing of the steepest radial axes; I-S value: Inferior-superior asymmetry in keratometry; BFS 8.0 $\mathrm{mm}$ : Best fit sphere to $8.0 \mathrm{~mm}$ zone; ART: Ambrosio relational thickness calculated for the average and maximum progression indices (ART avg and ART max); PRFI: Pentacam random forest index; BAD (v3): Belin/Ambrosio deviation index (third generation [version 3])

its progression, along with the intrinsic susceptibility for biomechanical decompensation, is clarified. Such knowledge will raise the bar of safety and efficiency for selecting and planning refractive and therapeutic procedures.

\section{REFERENCES}

1. Wilson SE, Ambrosio R Jr. Computerized corneal topography and its importance to wavefront technology. Cornea 2001 Jul;20(5):441-454.

2. Ambrosio R Jr, Belin MW. Imaging of the cornea: topography vs tomography. J Refract Surg 2010 Nov;26(11):847-849.

3. Ambrosio R Jr, Wilson SE. Complications of laser in situ keratomileusis: etiology, prevention, and treatment. J Refract Surg 2001 May-Jun;17(3):350-379.

4. Ambrosio R Jr, Dawson DG, Belin MW. Association between the percent tissue altered and post-laser in situ keratomileusis ectasia in eyes with normal preoperative topography. Am J Ophthalmol 2014 Dec;158(6):1358-1359.

5. Luce DA. Determining in vivo biomechanical properties of the cornea with an ocular response analyzer. J Cataract Refract Surg 2005 Jan;31(1):156-162.

6. Moreno-Montanes J, Maldonado MJ, Garcia N, Mendiluce L, Garcia-Gomez PJ, Segui-Gomez M. Reproducibility and clinical relevance of the ocular response analyzer in nonoperated eyes: corneal biomechanical and tonometric implications. Invest Ophthamol Vis Sci 2008 Mar;49(3):968-974.

7. Ambrosio R Jr, Ramos I, Luz A, Faria FC, Steinmueller A, Krug M, Belin MW, Roberts CJ. Dynamic ultra high speed Scheimpflug imaging for assessing corneal biomechanical properties. Rev Bras Oftalmol 2013 Mar-Apr;72(2):99-102.

8. Huseynova T, Waring GO 4th, Roberts C, Krueger RR, Tomita M. Corneal biomechanics as a function of intraocular pressure and pachymetry by dynamic infrared signal and Scheimpflug imaging analysis in normal eyes. Am J Ophthalmol 2014 Apr;157(4):885-893.

9. Fontes BM, Ambrosio R Jr, Jardim D, Velarde GC, Nose W. Ability of corneal biomechanical metrics and anterior segment data in the differentiation of keratoconus and healthy corneas. Arq Bras Oftalmol 2010 Jul-Aug;73(4):333-337.

10. Fontes BM, Ambrosio R Jr, Salomao M, Velarde GC, Nose W. Biomechanical and tomographic analysis of unilateral keratoconus. J Refract Surg 2010 Sep;26(9):677-681.

11. Ambrosio R Jr, Lopes BT, Faria-Correia F, Salomao MQ, Buhren J, Roberts CJ, Elsheikh A, Vinciguerra R, Vinciguerra P. Integration of scheimpflug-based corneal tomography and biomechanical assessments for enhancing ectasia detection. J Refract Surg 2017 Jul;33(7):434-443.

12. Vinciguerra R, Ambrosio R Jr, Elsheikh A, Roberts CJ, Lopes B, Morenghi E, Azzolini C, Vinciguerra Pl. Detection of keratoconus with a new biomechanical index. J Refract Surg 2016 Dec;32(12):803-810.

13. Ambrosio R Jr, Caiado AL, Guerra FP, Louzada R, Sinha RA, Luz A, Dupps WJ, Belin MW. Novel pachymetric parameters based on corneal tomography for diagnosing keratoconus. J Refract Surg 2011 Oct;27(10):753-758.

14. Ambrosio R Jr, Belin MW. Enhanced screening for ectasia risk prior to laser vision correction. Int J Keratoconus Ectatic Corneal Dis 2017 Jan-Jun;6(1):23-33.

15. Binder PS, Lindstrom RL, Stulting RD, Donnenfeld E, $\mathrm{Wu} \mathrm{H}$, McDonnell P, Rabinowitz Y. Keratoconus and corneal ectasia after LASIK. J Cataract Refract Surg 2005 Nov;31(11): 2035-2038.

16. Ambrosio R Jr, Randleman JB. Screening for ectasia risk: what are we screening for and how should we screen for it? J Refract Surg 2013 Apr;29(4):230-232. 
17. Guerra G, Oliveira VB, Ferreira I, Ramos I, Belin MW, Ambrosio R Jr. Subclinical keratoconus detection in identical twins. Int J Keratoconus Ectatic Corneal Dis 2016 Jan-Apr;5(1):35-39.

18. Tuft SJ, Hassan H, George S, Frazer DG, Willoughby CE, Liskova P. Keratoconus in 18 pairs of twins. Acta Ophthalmol 2012 Sep;90(6):e482-e486.

19. Rabinowitz YS, Rasheed K. KISA\% index: a quantitative videokeratography algorithm embodying minimal topographic criteria for diagnosing keratoconus. J Cataract Refract Surg 1999 Oct;25(10):1327-1335.
20. Holland DR, Maeda N, Hannush SB, Riveroll LH, Green MT, Klyce SD, Wilson SE. Unilateral keratoconus. Incidence and quantitative topographic analysis. Ophthalmology 1997 Sep;104(9):1409-1413.

21. Fontes BM, Ambrosio R Jr, Salomao M, Velarde GC, Nose W. Ambrosio R Jr, Correia FF, Lopes B, Salomao MQ, Luz A, Dawson DG, Elsheikh A, Vinciguerra R, Vinciguerra P, Roberts CJ. Corneal biomechanics in ectatic diseases: refractive surgery implications. Open Ophthalmol J 2017 Jul;11: 176-193. 